\title{
Histopathological Patterns of Endometrial Lesions in Patients with Abnormal Uterine Bleeding in a Cosmopolitan Population
}

\author{
Gerald Dafe Forae, Jonathan Umezuluike Aligbe \\ Department of Pathology, University of Benin Teaching Hospital, Benin-City and Ashama Foundation Diagnostic Centre, Benin-City, Edo, Nigeria
}

\section{A B S T R A C T}

Background: Endometrial diseases ranked among the most common gynecological disorders that affect women globally. These diseases cut across all age groups and contribute significantly to increased maternal morbidity and mortality. Due to the wide range of histopathological patterns, the need for urgent diagnosis and treatment cannot be overemphasized. Aim: The aim of this study is to highlight the frequency and histological types and patterns of the endometrial lesions in patients with abnormal uterine bleeding (AUB) in private practice in Benin-City, Nigeria. Materials and Methods: $\mathrm{H}$ and $\mathrm{E}$ stained-slides of endometrial biopsies diagnosed at the Ashamas foundation histopathology diagnostic center in Benin-City for 10 years were archived and studied. Request forms were analyzed for clinical bio-data, diagnosis and type of biopsies carried out. Data were entered using Micro-soft Excel package and transferred to statistics software (statistical package for the social sciences Version 17, SPSS Incorperated, Chicago Illinois, USA) for descriptive analysis. Results: In all, 231endometrial lesions were received. Of these, $207 / 231$ (89.6\%) cases were seen in reproductive and perimenopausal age groups while 24/231 (10.4\%) was encountered in postmenopausal age group. The age range and peak age incidence was 17-86 years and fourth decade respectively. The mean age was 38.8 (6.8) years In all 231 endometrial lesions, product of conception was the most common finding observed ( $n=64 / 231$; $27.7 \%$ ) in reproductive and pre-menopausal women. While the most frequently encountered lesion in postmenopausal women was complex endometrial hyperplasia $(n=6 / 231 ; 2.6 \%)$. Conclusion: Histopathological patterns of endometrial biopsy and curettage of women presenting with AUB is variable. Product of conception was the most commonly encountered among reproductive women. Nevertheless, endometrial hyperplasia was most frequent in perimenopausal age group.

KEY WORDS: Cancer, endometrium, histopathology, lesions, private practice

\section{INTRODUCTION}

Endometrial diseases ranked among the most common gynecological disorders that affect women globally. ${ }^{[1]}$ These diseases cut across all age groups and contribute significantly to increased maternal morbidity and mortality. Most females with endometrial diseases present with abnormal uterine bleeding (AUB). ${ }^{[1,2]}$ Thus, AUB justify the need for urgent diagnosis. This is so because of the wide range of histopathological patterns of endometrium diseases. These lesions range from simple endometrial hyperplasia to more complex disorders including endometrial carcinoma. ${ }^{[2]}$ Majority of these lesions can only be diagnosed by sampling the endometrium. Endometrial

\begin{tabular}{|l|l|}
\hline \multicolumn{2}{|c|}{ Access this article online } \\
\hline Quick Response Code & Website: \\
& www.jbcrs.org \\
\cline { 2 - 2 } & DOI: \\
\hline
\end{tabular}

biopsy and curettage are two most important sampling methods for definitive diagnosis of the lesions. ${ }^{[3]}$

Studies have shown that histopathological patterns of diagnosis varies with respect to the age of patients. ${ }^{[4]}$ Most young women of reproductive age present more commonly with changes associated with hormonal imbalance. ${ }^{[4]}$ However, older women of premenopausal and postmenopausal age group present more commonly with endometrial hyperplasia and endometrial carcinoma. ${ }^{[4,5]}$ Reports have it that cancer of the endometrium is the most common gynecological malignancy in developed countries and the second most common gynecological malignancy in developing countries after cancer of the cervix. ${ }^{|5|}$ Studies in the United State confirm that endometrial cancer constituted $6 \%$ of all gynecological cancer and the third most common cause of death resulting from gynecological malignancy after ovarian and cervical cancers. ${ }^{[6]}$ Globally, about $10 \%$ of

$$
\begin{array}{r}
\text { Address for correspondence } \\
\text { Dr. Gerald Dafe Forae, } \\
\text { Department of Pathology, University of Benin Teaching Hospital, } \\
\text { Benin-City, Edo, Nigeria. } \\
\text { E-mail: jforae2000@yahoo.com }
\end{array}
$$


all perimenopausal and postmenopausal women with AUB present with endometrial cancer. ${ }^{|7|}$

This paper intends to establish a database with respect to histopathological patterns and frequencies of endometrial diseases in women of various age groups presenting with AUB in our locale.

\section{MATERIALS AND METHODS}

\section{Study setting and design}

All endometrial curettage and biopsies received at the Ashamas Foundation Histopathology Diagnostic Center, Benin City, Edo State, Nigeria from January 2001 to December 2010 were studied. This center is a foremost private center in Benin-City metropolis and Edo State offering histopathology services. Most of these specimens were sent by Gynecologists having private and public group practice in Benin-City metropolis, its environs and other parts of Edo State. The cases for the study were identified and extracted from the histopathology surgical daybooks of Ashamas foundation diagnostic center. Information regarding the age, clinical history, digital rectal examination, clinical diagnosis was obtained. Cervical lesions were histological diagnosed by two experienced pathologists using the World Health Organization recommendations.

\section{Specimen sampling and laboratory procedure}

All specimens sent for histology were fixed in $10 \%$ formalin solution, processed with Histokinette automated tissue processor, paraffin embedded and sectioned at 3-5 microns using the microtome machine before staining with $\mathrm{H}$ and $\mathrm{E}$. The results obtained were analyzed with respect to age and tumor type. Special stains including reticulin and periodic acid Schiff stains were used where necessary.

\section{Data management}

Data were entered using Micro-soft Excel package and transferred to statistics software (statistical package for the social sciences Version 17, SPSS Incorperated, Chicago Illinois, USA) for descriptive analysis.

\section{RESULTS}

During this 10 years period, a total of 231 endometrial lesions were received [Table 1]. Of these, 207/231 cases (89.6\%) were seen in reproductive and perimenopausal age groups while 24/231 (10.4\%) was encountered in postmenopausal women. The age range was $17-86$ years while the peak age incidence was $30-39$ years constituting $(n=72 / 231 ; 31.2 \%)$. The mean was 38.8 (6.8) years. In all 231 endometrial lesions seen in Table 2, product of conception was the most common finding $(n=64 / 231 ; 27.7 \%)$ observed in

\begin{tabular}{lc}
\hline \multicolumn{2}{c}{$\begin{array}{c}\text { Table 1: Frequency of histological patterns of endometrial } \\
\text { sampling in female patients presenting with abnormal } \\
\text { uterine bleeding }\end{array}$} \\
\hline $\begin{array}{l}\text { Histological types } \\
\text { Proliferative endometrium }\end{array}$ \\
$\begin{array}{l}\text { Secretory endometrium } \\
\text { Products of conception|complication of pregnancy }\end{array}$ \\
Simple endometrial hyperplasia & $52(22.5)$ \\
Cystic & $46(19.9)$ \\
Adenomatous & $64(27.7)$ \\
Complex endometrial hyperplasia without atypia & $7(3.1)$ \\
Cystic & $21(9.1)$ \\
Adenomatous & \\
Complex endometrial hyperplasia with atypia & $2(0.9)$ \\
Cystic & $3(1.3)$ \\
Adenomatous & $2(0.9)$ \\
Endometritis & $4(1.7)$ \\
Progesterone effect & $3(1.3)$ \\
Polyps & $1(0.4)$ \\
Hydratidiform mole & $7(3.1)$ \\
Adenoacathoma & $3(1.3)$ \\
Malignancy & $1(0.4)$ \\
Malignant mixed mullerian tumour & \\
Endometrial carcinoma & $3(1.3)$ \\
Choriocarcinoma & $4(1.7)$ \\
Atrophic endometrium & $1(0.4)$ \\
Inadequate & $6(2.6)$ \\
Total & $1(0.4)$ \\
\hline
\end{tabular}

\begin{tabular}{|c|c|c|c|c|}
\hline \multicolumn{5}{|c|}{$\begin{array}{c}\text { Table 2: Histological patterns and age distribution of } \\
\text { endometrial sampling in women presenting with abnormal } \\
\text { uterine bleeding }\end{array}$} \\
\hline \multirow[t]{2}{*}{ Lesions } & \multirow{2}{*}{$\begin{array}{c}\text { (reproductive) } \\
(\%)\end{array}$} & \multirow[b]{2}{*}{$\begin{array}{c}\text { (perimenopausal) } \\
(\%)\end{array}$} & 52 years+ & \multirow{2}{*}{$\begin{array}{c}\text { Total } \\
\%\end{array}$} \\
\hline & & & (postmenopausal) & \\
\hline Proliferative & 39 (16.9) & $13(5.6)$ & - & $52(22.5)$ \\
\hline Secreting & $39(16.9)$ & $7(3.0)$ & - & $46(19.9)$ \\
\hline \multirow{2}{*}{\multicolumn{5}{|c|}{ CEH }} \\
\hline & & & & \\
\hline Without atypia & $1(0.4)$ & $1(0.4)$ & $3(1.3)$ & $5(2.2)$ \\
\hline With atypia & - & $3(1.3)$ & $3(1.3)$ & $6(2.6)$ \\
\hline Endometritis & $1(0.4)$ & $2(0.9)$ & - & $3(1.3)$ \\
\hline Progesterone & $1(0.4)$ & - & - & $1(0.4)$ \\
\hline Atrophic & - & - & $6(2.6)$ & $6(2.6)$ \\
\hline Products & $52(22.5)$ & $12(5.2)$ & & $64(27.7)$ \\
\hline Polyps & $3(1.3)$ & $2(0.9)$ & $2(0.9)$ & $7(3.1)$ \\
\hline Adenoacanthoma & - & $1(0.4)$ & - & $1(0.4)$ \\
\hline \multicolumn{5}{|l|}{ H Mole } \\
\hline Partial & - & $2(0.9)$ & - & $2(0.9)$ \\
\hline Complete & $1(0.4)$ & - & 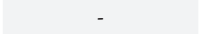 & $1(0.4)$ \\
\hline \multicolumn{5}{|l|}{ Malignancies } \\
\hline MMMT & - & $2(0.9)$ & $1(0.4)$ & $3(1.3)$ \\
\hline Endometrial CA & - & $1(0.4)$ & $3(1.3)$ & $4(1.7)$ \\
\hline Chorio & $1(0.4)$ & - & - & $1(0.4)$ \\
\hline Inadequate & - & - & $1(0.4)$ & $1(0.4)$ \\
\hline Total & 150 & 57 & 24 & 231 \\
\hline
\end{tabular}

reproductive and perimenopausal women. This is closely followed by proliferating endometrium and secretory endometrium accounting for $(n=52 / 231 ; 22.5 \%)$ and $(n=46 / 231 ; 19.9 \%)$, respectively. Simple endometrial hyperplasia was seen in $(n=23 / 231 ; 10.0 \%)$ cases. In reproductive and peri-menopausal age groups, complex endometrial hyperplasia was present in 5/231 cases $(2.2 \%) \%)$ out of which $3 / 231(1.3 \%)$ showed atypia. Other 
less commonly seen cases include polyps, endometritis, hydatidiform mole constituting $5 / 231(2.2 \%)$, and $3 / 231$ $(1.3 \%)$, respectively. Other extremely less common lesions include adenoacanthoma and progesterone effect accounting for $1 / 231(0.4 \%)$ each. Malignancies accounted for $4 / 231$ cases $(1.7 \%)$ with malignant mixed mullerian tissue as 2 cases $(0.9 \%)$, invasive endometrial carcinoma and choriocarcinoma each accounting for $1 / 231(0.4 \%) \%)$ respectively.

In all 231 endometrial lesions, the most frequently encountered lesion in postmenopausal women, was complex endometrial hyperplasia accounting for $(n=6 / 231$; 2.6\%). Of these cases, 3 (1.3\%) have atypia [Table 2]. Again atrophic endometrium also constituted $6(2.6 \%)$ cases. Five cases $(2.2 \%)$ were simple endometrial hyperplasia. Malignancies constituted $(n=4 ; 1.7 \%)$ with $(n=2 ; 0.9 \%)$ as invasive endometrial carcinoma and $(n=1 ; 0.4 \%)$ each as endometrial carcinoma in-situ and malignant mixed mullerian tumors. Polyps accounted for $(n=2 ; 0.9 \%)$ while 1 case was inadequate.

\section{DISCUSSION}

Histopathological diagnosis of endometrial biopsy and curettage is paramount in identifying the various diseases spectrum causing AUB. The causes vary with respect to the age of patients. Studies have shown that a significant number of women in their reproductive age groups presenting with AUB. Further studies have also documented increased incidence of intrauterine diseases presenting with AUB in perimenopausal age group. ${ }^{[8]}$

In this study, a gradual increase in women with AUB with respect to age of the patient was encountered. This was most commonly observed in women in their fourth decades of life constituting $43.3 \%$. However, this is slightly at variance with reports of other researchers where AUB was more commonly encountered in the fifth decades of life. . $^{[8,9]}$ Specifically, studies by Jairajpuri et al ${ }^{[8]}$ found $35.9 \%$ of AUB cases in women in their fifth decades. Again other studies revealed as high as $48.1 \%$ of AUB cases in women in their fifth decades. ${ }^{[9]}$ Still, other researchers reported $32.1 \%$ and $33.5 \%$ of AUB in women in their fifth decades. ${ }^{[10,11]}$

The reason for the early peak incidence of AUB in our study is partly attributable to the high incidence of illegal abortions and complication of pregnancy occurring in young adolescent girls and young women of reproductive age carrying unwanted pregnancy. This constituted 31\% and is the most common cause of AUB in this study. Several literature support the fact that pregnancy and its complication are the first consideration in women of reproductive age group. ${ }^{[12-15]}$ Whereas, in Caucasians series vast majority of AUB cases occurred in the fifth decades and may partly be due to decrease levels of estrogen in perimenopausal women and not due to illegal

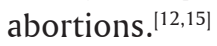

Product of conception was closely followed by proliferating endometrium and secretory endometrium accounting for $25.1 \%$ and $22.2 \%$ respectively. Similar report was documented for proliferating endometrium (21.7\%) and secretory endometrium (12.4\%) by other researchers. ${ }^{[13-15]}$ However, this study is at variance with study performed by Jairajpuri et al.$^{[8]}$ where secretory endometrium was the most common histopathological diagnosis followed by proliferative endometrium accounting for $28.9 \%$ and $24.9 \%$, respectively. Nevertheless, many other researchers have reported a wide range of variation for secretory endometrium ranging from 14 to $63.5 \% .^{[13-16]}$ Notwithstanding, our study of secretory endometrium falls within this series.

Prolong stimulation of the endometrium by estrogen results in formation of endometrial polyps. In this study, $3 \%$ of polyp was encountered. This is slightly higher than the $1.7 \%$ reported by Jairajpuri et al. ${ }^{[8]}$ However, this incidence is much lower than the $12 \%$ and $13 \%$ observed by Mirza et al. ${ }^{[16]}$ and Cornistescu et $a l .{ }^{[17]}$ the reason for this variation is not known but may be linked to geo-ethnical variation. Once more we observed that the prevalence of endometrial hyperplasia was common and accounted for $17 \%$. Now out of this, majority constituting $58.8 \%$ was simple endometrial hyperplasia and $41.2 \%$ was complex endometrial hyperplasia with majority seen in perimenopausal and postmenopausal women. A favorable comparison of $18.3 \%$ for endometrial hyperplasia was reported by Muzzafar et al. ${ }^{\left[{ }^{\mid 9]}\right.}$ However, a much lower and higher figures have been reported by many other researchers. ${ }^{[8,14,16,17]}$ Similar studies performed by other researchers reported that simple endometrial hyperplasia constituted $64.4 \%$ and $66.6 \%$ of all endometrial hyperplasia with the vast majority occurring in perimenopausal women. ${ }^{[8,14]}$

Malignancy is a major differential diagnosis in women of perimenopausal age group presenting with AUB. In this present study, the frequency of endometrial malignancy was low. This constituted $3.4 \%$ with endometrial carcinoma as the majority accounting for $1.7 \%$. Similar incidence of endometrial carcinoma was reported by Sarwa et al. ${ }^{[1]}$ Nevertheless, a much higher values of $4.4 \%$ for endometrial carcinoma have been documented by Saraswathi et al. ${ }^{[11]}$ on the contrary a much lower value $0.5 \%$ has been documented for endometrial carcinoma by Jairajpuri et al. ${ }^{[8]}$ with the majority in the perimenopausal age group. Malignant mixed mesodermal tumour and choriocarcinomas were rare findings encountered in this study. This is corroborated with reports from other researchers globally. 
Study of atrophic endometrium constituted $2.4 \%$ with most cases presenting in the postmenopausal age group. This is similar to other report by other researchers. ${ }^{[11]}$ Conversely, this is in discordance with reports by Mirza et al. ${ }^{[16]}$ where it constituted $7 \%$ with most of the cases seen in postmenopausal age group. Other rarer cases encountered were cases of chronic endometritis accounting for $1.3 \%$ in this study. This again is lower than report of other researchers. ${ }^{[18,19]}$

\section{CONCLUSION}

Histopathological patterns of endometrial biopsy and curettage of women presenting with AUB is variable. This ranges from simple physiological to much more complex pathological lesions. Vast majority of the lesions causing AUB encountered in this study were products of conception seen most commonly in reproductive women. However, endometrial hyperplasia was commonly seen in perimenopausal age group and few cases of endometrial carcinoma were also seen in perimenopausal and postmenopausal women.

\section{REFERENCES}

1. Sarwar A, Haque A. Types and frequencies of pathologies in endometrial curretings of abnormal uterine bleeding. Int J Pathol 2005;3:65-70.

2. Crum CP, Hornstein MD, Nucci MR, Mutter GL. Hertig and beyond: A systematic and practical approach to the endometrial biopsy. Adv Anat Pathol 2003;10:301-18.

3. Khare A, Bansal R, Sharma S, Elhence P, Makkar S, Tyagi Y. Morphological spectrum of endometrium in patients presenting with dysfunctional uterine bleeding. People's Journal of Scientific Research 2012;5:13-6.

4. ACOG Committee on Practice Bulletins - Gynecology. American College of Obstetricians and Gynecologists. ACOG practice bulletin: Management of anovulatory bleeding. Int J Gynaecol Obstet 2001;72:263-71.

5. Jemal A, Bray F, Center MM, Ferlay J, Ward E, Forman D. Global cancer statistics. CA Cancer J Clin 2011;61:69-90.
6. Tracy N, Gibson J, Gurendra C. Causes of death at autopsy in hospitalized adult patients with diabetis mellitus: A study from a developing country. Int J Pathol 2007;6:114-7.

7. Symonds IM. Establishing outpatient hysteroscopy service. Curr Obstet Gynaecol 1999;9:158-62.

8. Jairajpuri ZS, Rana S, Jetley S. Atypical uterine bleeding-A histopathological audit of endometrium. A study of 638 cases. Al Ameen J Med Sci 2013;6:21-2.

9. Muzaffar M, Akhtar KA, Yasmin S, Mahmood-Ur-Rehman, Iqbal W, Khan MA. Menstrual irregularities with excessive blood loss: A clinico-pathological correlation. J Pak Med Assoc 2005;55:486-9.

10. Abdullah LS, Bondagji NS. Histopathological pattern of endometrial sampling performed for abnormal uterine bleeding. Bahrain Med Bull 2011;33:195-200.

11. Saraswathi D, Thanka J, Shalinee R, Aarthi R, Jaya V, Kumar PV. Study of endometrial pathology in abnormal uterine bleeding. Obstet Gynaecol India 2011;61:424-30.

12. Davey DA. Dysfunctional uterine bleeding. In: Whitfield CR, editor. Dewhurst's Textbook of Gynaecology for Postgraduates. Glasgow: Blackwell Science; 1997. p. 590-608.

13. Bhosle A, Fonseca M. Evaluation and histopathological correlation of abnormal uterine bleeding in perimenopausal women. Bombay Hosp J 2010;52:69-72.

14. Takreem A, Danish N, Razaq S. Incidence of endometrial hyperplasia in 100 cases presenting with polymenorrhagia/menorrhagia in perimenupausal women. J Ayub Med Coll Abbottabad 2009;21:60-3.

15. Patil SG, Bhute SB, Inamdar SA, Acharya NS, Shrivastava DS. Role of diagnostic hysteroscopy in abnormal uterine bleeding and its histopathologic correlation. J Gynecol Endosc Surg 2009;1:98-104.

16. MirzaT,Akram S, MirzaA,AzizS, Mirza T, MustansarT. Histopathological pattern of abnormal uterine bleeding in endometrial biopsies. J Basic Appl Sci 2012;8:114-7.

17. Cornițescu FI, Tănase F, Simionescu C, Iliescu D. Clinical, histopathological and therapeutic considerations in non-neoplastic abnormal uterine bleeding in menopause transition. Rom J Morphol Embryol 2011;52:759-65.

18. Baral R, Pudasini S. Histopathological pattern of endometrial samples in abnormal uterine bleeding. J Pathol Nepal 2011;1:13-6.

19. Ara S, Roohi M. Abnormal uterine bleeding; Histopathological diagnosis in conventional dilation and curettage. Prof Med J 2011;18:587-91.

How to cite this article: Forae GD, Aligbe JU. Histopathological patterns of endometrial lesions in patients with abnormal uterine bleeding in a cosmopolitan population. J Basic Clin Reprod Sci 2013;2:101-4.

Source of Support: Nil, Conflict of Interest: None declared 